\title{
Urinary Excretion of Silicon in Men, Non-pregnant Women, and Pregnant Women: a Cross-sectional Study
}

\author{
Catarina Magnusson $^{1}$ (D) $\cdot$ Ravin Jugdaohsingh ${ }^{2} \cdot$ Lena Hulthen $^{3} \cdot$ Anna Westerlund $^{1} \cdot$ Jonathan J. Powell $^{2}$. \\ Maria Ransjö ${ }^{1}$
}

Received: 11 April 2019 / Accepted: 14 June 2019 / Published online: 29 June 2019

(C) The Author(s) 2019

\begin{abstract}
Silicon is a trace element found mainly in plant-based food and proposed to be beneficial for bone health. Urinary excretion of Si has been shown to be a surrogate measure of its uptake in the gastrointestinal tract. The objective of this study was to describe and compare the levels of urinary Si excretion, and consequently Si uptake, in Swedish men, non-pregnant women, and pregnant women. No formal assessment of dietary Si intake was carried out in this study. This cross-sectional study included 89 men, 42 non-pregnant women, and 60 pregnant women. The subjects collected urine over a 24-h period and the samples were assayed for total Si using inductively coupled plasma optical emission spectrometry. The excretion levels of creatinine were used to validate the completeness of the urine sample collections. The mean 24-h urinary excretions of Si were $7.8 \mathrm{mg}$ for the cohort of young men, $7.6 \mathrm{mg}$ for the cohort of non-pregnant women, and $12.4 \mathrm{mg}$ for the cohort of pregnant women. Creatinine excretion was similar between pregnant and non-pregnant women (10.4 vs. $10.8 \mathrm{mmol} /$ day) and significantly higher in men (15.4 mmol/day). The pregnant women excreted significantly higher levels of Si than the young men and non-pregnant women, respectively $(p<0.05)$. The higher urinary excretion of Si by pregnant women compared with men and non-pregnant women is a novel finding possibly caused by temporary physiological changes during pregnancy such as increased gastrointestinal uptake of Si, altered bone metabolism, and increased renal excretion of Si.
\end{abstract}

Keywords Silicon · Pregnancy · Urinary excretion · Trace element · Bone metabolism

\section{Introduction}

Bone is a metabolically active tissue, and bone mass is influenced by hormonal status, physical activity, and nutrition [1]. Calcium and vitamin D are essential nutrients for promoting bone health. Additional dietary factors of importance for bone health are macronutrients such as proteins, micronutrients such as vitamins (e.g. vitamin $\mathrm{C}$ ), minerals (e.g. $\mathrm{Mg}$ and $\mathrm{P}$ ), and various trace elements (e.g. $\mathrm{Zn}$ and $\mathrm{Cu}$ ) [2]. Another nutrient

\footnotetext{
Catarina Magnusson

catarina.magnusson@gu.se

Ravin Jugdaohsingh

rj328@cam.ac.uk

Lena Hulthen

lena.hulthen@medfak.gu.se

Anna Westerlund

anna.westerlund@odontologi.gu.se

Jonathan J. Powell

jjp37@cam.ac.uk
}

with possible beneficial properties for bone health is the element silicon ( $\mathrm{Si}$ ). Silicon has been detected in animal bone tissues [3, 4] and localised to the active calcification areas [5]. Early Si deprivation studies in chicks and young rats demonstrated impaired skeletal development and growth of the long bones $[6,7]$. In vitro studies have demonstrated that Si stimulates proliferation of osteoblasts, has positive effects on collagen synthesis [8], and inhibits osteoclast differentiation and bone resorption [9]. In line with this, in the Framingham

\author{
Maria Ransjö \\ maria.ransjo@gu.se
}

1 Department of Orthodontics, Institute of Odontology, The Sahlgrenska Academy, University of Gothenburg, PO Box 450, 405 30 Gothenburg, Sweden

2 Biomineral Research Group, Department of Veterinary Medicine, University of Cambridge, Madingley Road, Cambridge CB3 0ES, UK

3 Department of Internal Medicine and Clinical Nutrition, Institute of Medicine, The Sahlgrenska Academy, University of Gothenburg, Box 459, 40530 Gothenburg, Sweden 
Offspring Cohort, a positive association between Si intake and hip bone mineral density was demonstrated in men and premenopausal women, although not in post-menopausal women [10]. Taken together, these studies suggest that Si has positive effects on bone formation and skeletal development.

$\mathrm{Si}$ is abundant in the environment and a common dietary component. Whilst there are many Si compounds, the primary specie that humans can assimilate is the soluble orthosilicic acid $(\mathrm{OSA}),\left[\mathrm{Si}(\mathrm{OH})_{4}\right][11,12]$. The dietary intake of $\mathrm{Si}$ in Western populations is $20-50 \mathrm{mg} /$ day $(0.7-1.8 \mathrm{mmol} /$ day) [13-15]. The highest levels of Si are found in cereal-based products, whereas fruits and vegetables have highly variable levels [16] and animal-derived products are low in $\mathrm{Si}$ [13]. Whilst the Si content of tap water varies, depending on the surrounding geology, it contributes considerably to daily $\mathrm{Si}$ intake due to the large volumes consumed [16]. Alcoholic beverages have moderate to high concentrations of Si [13, 16]; beer provides substantial amounts of bioavailable $\mathrm{Si}$ as it is brewed from malted barley $[17,18]$. However, foods that have high levels of $\mathrm{Si}$ are not necessarily good sources because the absorption of the Si species present in the food depends on how readily they are degraded to OSA in the gastrointestinal tract [19]. The absorption of OSA is reflected by a rapid and marked increase in the serum level of Si following ingestion [12]. Since the kidneys serve as the main route of excretion of $\mathrm{Si}$ and the majority of the absorbed $\mathrm{Si}$ is readily excreted, urinary levels of Si can be used as a surrogate marker of Si uptake [12, 20]. Fifty to sixty percent of the ingested $\mathrm{Si}$ is estimated to be absorbed and excreted in urine, whilst the remainder is not absorbed and found in the faecal excretion [21]. As few studies have investigated 24 $\mathrm{h}$ urinary levels of $\mathrm{Si}$ and no previous study has reported on Si excretion levels during pregnancy, the aim of the present study was to investigate $\mathrm{Si}$ excretion levels in 24-h urine samples collected from Swedish cohorts of young men, nonpregnant women, and pregnant women, to examine genderand pregnancy-related differences.

\section{Subjects and Methods}

\section{Subjects}

The subjects in the present study were originally participants in the three different epidemiological studies.

\section{Cohort I}

Data and urine samples from 89 young men, who were originally participants in the Gothenburg Osteoporosis and Obesity Determinants (GOOD) study [22], were used in the present study. The GOOD study was conducted to identify environmental and genetic factors involved in bone and fat mass regulation among young Swedish men. Subjects that met the inclusion criterion of $>18$ and $<20$ years of age were randomly selected from a national population register and asked to participate. No additional exclusion criteria were set. In total, 1068 men from the greater area of Gothenburg were included in the GOOD study and data were collected in 2005. A representative cross section of subjects from the original study was selected randomly (every tenth subject) to determine the dietary intake and renal excretion levels of $\mathrm{Na}$ and $\mathrm{K}$ among young Swedish men [23], and these were the subjects included in the present study. In addition to recorded information about their dietary intake by food frequency questionnaire, the subjects also collected urine over a 24 -h period.

\section{Cohort II}

A sub-group of 42 women, formerly participants in a study describing obesogenic trends in two generations of Swedish women [24], were used in the present study. In the original study, 1270 women aged 38 or 50 years were selected based on their date of birth from a population register and were examined either in 1968/1969 or 2004/2005. Data from the last subjects included in to the group and examined in 2004/2005, comprised 26 women aged 50 years and 16 women aged 38 years, were used in the present study. This subgroup of 42 women was comparable with the original group examined. Weekday dietary habits were recorded as $24-\mathrm{h}$ recalls and urine was collected over a $24-\mathrm{h}$ period.

\section{Cohort III}

Data and urine samples from 60 pregnant women, originally participants in a cross-sectional study (unpublished) completed in 2006 at Gothenburg University, were also analysed in the present study. The aim of the original study was to determine the iodine status and thyroid functions of pregnant women. The inclusion criteria were gestation age between week 8 and week 15 and no pregnancy or lactation in the previous 18 months. No other exclusion criteria were applied. Anthropometric measurements and whole blood and 24-h urine collections were conducted. The consumption of foods with high levels of iodine, such as fish and dairy products, was collected by a food frequency questionnaire and the intake of supplements was also recorded.

\section{Urine Collections and Analyses}

Urine collection was carried out in the same way for all three cohorts. The 24-h collection period started after the first void urine excretion on day 1 and finished after the first void urine excretion on day 2. Urine was collected in acid-washed plastic containers. The total excretion volume was determined, and a 10 -ml aliquot was stored at $-20^{\circ} \mathrm{C}$ until analysis. 
Incomplete 24-h urine collections were identified in all three cohorts based on their urinary creatinine values [25]. Creatinine was measured according to the method routinely used at the accredited Laboratory of Clinical Chemistry at Sahlgrenska University Hospital, Gothenburg, Sweden. Samples with creatinine values outside the normal reference range for men, $8.8-17.6 \mathrm{mmol} / \mathrm{day}$, and for women, 7.0 $15.8 \mathrm{mmol} /$ day, were excluded.

Total $\mathrm{Si}$ analysis was conducted by the Biomineral Research Group (Cambridge, UK). Frozen urine samples were defrosted at $4{ }^{\circ} \mathrm{C}$. After thorough mixing, a 2-ml aliquot of each sample was diluted with $4 \mathrm{ml}$ of $0.7 \%$ nitric acid diluent, prepared by adding $5 \mathrm{ml}$ of high-purity $\mathrm{HNO}_{3}(69 \%$ p.a. plus; Sigma-Aldrich Chemical Co., Gillingham, UK) to a total of $495 \mathrm{ml}$ of ultra-high-purity water $(18 \mathrm{M} \Omega \mathrm{cm})$. Total $\mathrm{Si}$ analysis was carried out on an inductively coupled plasma optical emission spectrometer (ICP-OES, Jobin Yvon 20002, Instrument SA, Longjumeau, France), equipped with a concentric nebuliser and cyclonic spray chamber. Sample flow rate was $1 \mathrm{ml} / \mathrm{min}$. Peak profiles were used as previously described [26], with a window size of $0.08 \mathrm{~nm}(0.04 \mathrm{~nm}$ either side of the peak) with 21 increments per profile, and an integration time of $0.5 \mathrm{~s}$ per increment. The 251.611-nm Si analytical line was used. Samples were analysed together with sample blanks (i.e. diluent alone) and with pooled samplebased standards (0-40 ppm Si). Pooled sample-based standards were prepared by pooling $1 \mathrm{ml}$ of each of the diluted urine sample and spiking 5-10-ml aliquots of this pooled sample with Si from a stock Si ICP standard solution (1000 ppm Si; Merck Ltd, Poole, UK). Note that ICP-OES quantifies the total amount of elemental $\mathrm{Si}$ and gives no information about its chemical composition/speciation.

\section{Calculations and Statistical Analysis}

Due to missing total urine volume values $(n=3)$, creatinine values lying outside the normal range $(n=2)$, and extremely low urinary Si output $(n=1)$, the final cohorts consisted of 86 young men, 40 non-pregnant women, and 59 pregnant women. Body mass index (BMI) was calculated as body weight $(\mathrm{kg})$ divided by the height squared $\left(\mathrm{m}^{2}\right)$. Data were analysed and graphs were made using the PRISM 7 software (GraphPad Software Inc., San Diego, CA, USA). Normal distribution of the data was tested with the Shapiro-Wilk normality test. Confidence interval was set to $95 \%$. Data that passed the normality test were compared with one-way ANOVA followed by Tukey's multiple comparison test. Nonparametric data were compared with Kruskal-Wallis oneway ANOVA on ranks followed by Dunn's multiple comparison test. Differences in subject characteristics and urinary $\mathrm{Si}$ excretion values between the sub-groups of non-pregnant women of different ages were tested with the Mann-Whitney $U$ test. Comparison of the urinary Si levels between the sub- groups of pregnant women taking supplements and those not taking supplements was tested with an unpaired $t$ test. Association between BMI and Si excretion was tested with Pearson's correlation coefficient.

\section{Results}

\section{Subjects' Characteristics}

The characteristics of the three cohorts are listed in Table 1 . The group of men was significantly younger, taller, and heavier than the two groups of women. No difference in the BMI was found between the three groups. There was no significant difference in characteristics between the sub-groups of nonpregnant women aged 38 years and 50 years.

\section{Urinary Excretion of Si}

Total urine volume was significantly lower for men compared with non-pregnant women, but not compared with pregnant women. Whereas no significant difference was found in total urine volume between the groups of women (Table 2). The concentration of $\mathrm{Si}$ in urine were significantly different between all three cohorts, with the lowest Si concentration measured in non-pregnant women and the highest in pregnant women (Table 2). As pregnant women were younger than non-pregnant women, we subdivided the non-pregnant women into two groups. However, no significant differences in urine volume or urinary $\mathrm{Si}$ concentration, and therefore no significant difference in the total 24-h urinary Si excretion, were found between the sub-groups of non-pregnant women aged 38 years and 50 years (Table 2). Creatinine excretion was similar between pregnant and non-pregnant women (10.4 vs. $10.8 \mathrm{mmol})$ and significantly higher in men $(15.4 \mathrm{mmol}$; Table 2).

With regard to the 24-h urinary excretion of $\mathrm{Si}$, the nonpregnant women and men exhibited a similar distribution pattern (Fig. 1a). However, for the pregnant women, the distribution was shifted towards higher Si levels, as compared with the other two groups (Fig. 1a). The inter-quartile ranges for 24-h Si excretion were as follows: 5.6-9.3 $\mathrm{mg}$ for the group of young men; $5.4-9.7 \mathrm{mg}$ for the non-pregnant women; and 8.6-14.7 mg for the pregnant women (Fig. 1b). Mean ( \pm SD) 24-h urinary $\mathrm{Si}$ excretion levels were as follows: 7.8 ( \pm $3.0) \mathrm{mg}$ for the cohort of young men; $7.6( \pm 2.9) \mathrm{mg}$ for the non-pregnant women; and $12.4( \pm 4.7) \mathrm{mg}$ for the cohort of pregnant women, significantly higher $(p<0.05)$ compared with young men and non-pregnant women (Table 2).

Seventy-two percent of the pregnant women $(n=43)$ complemented their diet with supplements on a daily basis. The most common of which was multivitamins, followed by iron and omega-3. The majority of these products did not 
contain any $\mathrm{Si}$, although in some cases $\mathrm{Si}$ was present in negligible amounts as an additive that was needed during formulation. However, there were no significant differences in the urinary Si levels between the pregnant women taking supplements and those not taking supplements, with mean $( \pm \mathrm{SD})$ of $12.8( \pm 4.7)$ vs. $11.4( \pm 4.7) \mathrm{mg} / 24 \mathrm{~h}$, respectively (Fig. 2$)$.

\section{Discussion}

Urinary levels of Si have never before been reported in pregnant women and the results of the present study revealed significantly higher 24-h urinary excretion of Si in pregnant women, compared with non-pregnant women and young men. The increased urinary Si output in the group of pregnant women was not due to an increase in urine volume but rather to a higher concentration of $\mathrm{Si}$ in the urine. This may be due to physiological changes during pregnancy such as increased uptake of $\mathrm{Si}$ in the gastrointestinal tract, altered renal excretion of $\mathrm{Si}$, or an increase in bone turnover resulting in an increase in the release of Si from bone and other connective tissues. We also cannot rule out an excessive intake of Si-rich foods as no formal assessment of dietary Si intake was carried out in this study.

Several studies have investigated urinary excretion of $\mathrm{Si}$ in relation to different diets, dietary supplementation, and absorption of OSA [17, 21, 27]. Many of the previous studies report $\mathrm{Si}$ levels in urine collected over a shorter period than $24 \mathrm{~h}$ and therefore, data from these studies cannot be used for comparison. However, the Si levels in the present study agree with the $\mathrm{Si}$ concentrations reported in unaffected 24-h urine collections from healthy men and non-pregnant women in a previously conducted study [28]. A study carried out on uraemic patients showed significantly lower 24-h urinary excretion of Si compared with all three cohorts in the present study, confirming that an adequate glomerular filtration rate is a prerequisite for normal urinary Si excretion levels [20]. However, the cohort of pregnant women in the present study had significantly higher total 24-h urinary Si levels compared with healthy men and non-pregnant women presented in the reports of Dobbie and Smith $[20,28]$. Another earlier study in healthy individuals reported significantly higher $(33.1 \mathrm{mg})$ 24-h urinary Si excretion levels than those in the present study [29]. The reason for the discrepancy in Si excretion levels is unknown but the analysis of $\mathrm{Si}$ is challenging due to the high risk of contamination, as $\mathrm{Si}$ is ubiquitous in the environment.

The mechanisms underlying the elevated levels of urinary $\mathrm{Si}$ excretion in pregnant women are unknown. A possible explanation for the increased urinary output of $\mathrm{Si}$ in the pregnant women is higher $\mathrm{Si}$ intake. Our study cannot comprehensively address this question, as the collection of dietary intake data in the pregnant women was selective and focused on foods with high levels of iodine. A limitation of the study is therefore that a comparison of dietary Si intake between the groups cannot be performed. 
Table 2 Urinary profiles of the study population sub-groups

\begin{tabular}{|c|c|c|c|c|c|c|c|c|c|c|c|c|c|c|c|}
\hline & \multirow{2}{*}{\multicolumn{3}{|c|}{$\begin{array}{l}\text { Young men } \\
\text { All (a) } \\
N=86\end{array}$}} & \multicolumn{9}{|c|}{ Non-pregnant women } & \multirow{2}{*}{\multicolumn{3}{|c|}{$\begin{array}{l}\text { Pregnant women } \\
\text { All (e) } \\
N=59\end{array}$}} \\
\hline & & & & \multicolumn{3}{|c|}{$\begin{array}{l}\text { All (b) } \\
N=40\end{array}$} & \multicolumn{3}{|c|}{$\begin{array}{l}38 \text {-year-olds (c) } \\
N=15\end{array}$} & \multicolumn{3}{|c|}{$\begin{array}{l}50 \text {-year-olds (d) } \\
N=25\end{array}$} & & & \\
\hline & Mean & $\mathrm{SD}$ & Range & Mean & SD & Range & Mean & $\mathrm{SD}$ & Range & Mean & $\mathrm{SD}$ & Range & Mean & SD & Range \\
\hline $\begin{array}{l}\text { Total 24-h urinary } \\
\text { creatinine (mmol) }\end{array}$ & $15.4^{\mathrm{b}, \mathrm{c}, \mathrm{d}, \mathrm{e}}$ & 3.6 & $6.2-25.5$ & $10.4^{\mathrm{a}}$ & 2.5 & $6.3-20.4$ & $11.2^{\mathrm{a}}$ & 3.4 & $6.7-20.4$ & $9.9^{\mathrm{a}}$ & 1.8 & $6.3-12.8$ & $10.8^{\mathrm{a}}$ & 2.2 & $6.7-17.1$ \\
\hline $\begin{array}{l}\text { Total } 24 \text {-h urine } \\
\text { volume (l) }\end{array}$ & $1.5^{\mathrm{b}, \mathrm{d}}$ & 0.7 & $0.4-4.1$ & $2.1^{\mathrm{a}}$ & 0.8 & $1.1-5.3$ & 1.7 & 0.7 & $1.1-3.8$ & $2.3^{\mathrm{a}}$ & 0.9 & $1.3-5.3$ & 1.8 & 0.7 & $0.5-3.6$ \\
\hline $\begin{array}{l}\text { 24-h urinary } \mathrm{Si} \\
\text { concentration (mg/l) }\end{array}$ & $5.9^{\mathrm{b}, \mathrm{d}, \mathrm{e}}$ & 3.1 & $1.6-19.1$ & $4.0^{\mathrm{a}, \mathrm{e}}$ & 1.7 & $1.1-8.7$ & $4.4^{\mathrm{e}}$ & 1.3 & $2.4-7.0$ & $3.8^{\mathrm{a}, \mathrm{e}}$ & 1.8 & $1.1-8.7$ & $7.5^{\mathrm{a}, \mathrm{b}, \mathrm{c}, \mathrm{d}}$ & 2.9 & $2.7-16.1$ \\
\hline $\begin{array}{l}\text { Total 24-h urinary Si } \\
\quad \text { excretion }(\mathrm{mg})\end{array}$ & $7.8^{\mathrm{e}}$ & 3.0 & $2.4-17.8$ & $7.6^{\mathrm{e}}$ & 2.9 & $2.5-15.8$ & $7.2^{\mathrm{e}}$ & 2.3 & $3.8-11.1$ & $7.9^{\mathrm{e}}$ & 3.2 & $2.5-15.8$ & $12.4^{\mathrm{a}, \mathrm{b}, \mathrm{c}, \mathrm{d}}$ & 4.7 & $4.7-24.5$ \\
\hline
\end{tabular}

Significantly different, $p<0.05$, compared with ${ }^{\mathrm{a}}$ young men (all), ${ }^{\mathrm{b}}$ non-pregnant women (all), ${ }^{\mathrm{c}}$ non-pregnant women aged 38 years, ${ }^{\mathrm{d}}$ non-pregnant women aged 50 years, and ${ }^{\mathrm{e}}$ pregnant women (all)

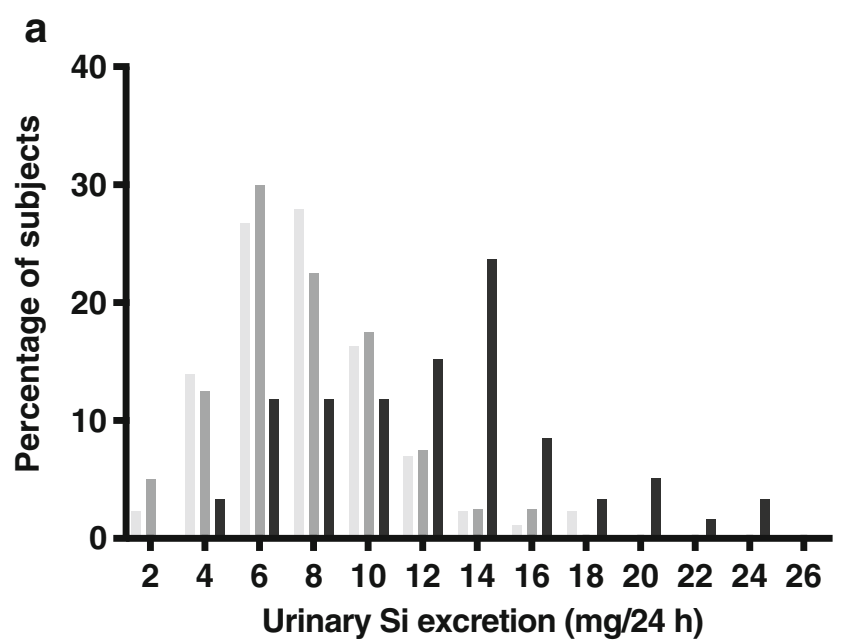

b

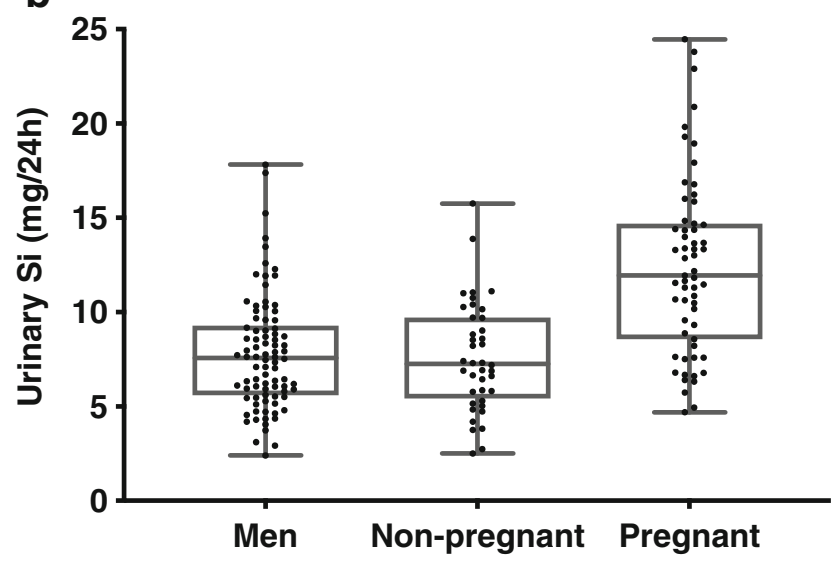

Fig. 1 a Distribution of relative frequencies of subjects with regard to 24$\mathrm{h}$ urinary $\mathrm{Si}$ excretion levels. The young men are represented by light grey bars —, non-pregnant women by dark grey bars —, and pregnant women

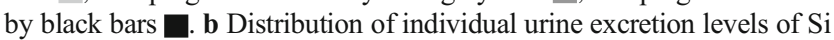
(mg/24 h) within each cohort. Each dot represents an individual subject, the whiskers shows the full data range (min to max), and the box shows the inter-quartile range
However, a general estimation of the food items recorded in the food frequency questionnaire for the pregnant women shows no distinguishable differences in habitual food intake compared with the other cohorts. The BMI of the pregnant women is not significantly different from that of the other two groups, nor above the limit for overweight which otherwise could be interpreted as deviating dietary habits compared with the other groups. No correlation between BMI and urinary Si excretion was found in the group of pregnant women. Furthermore, epidemiological studies have estimated a significantly higher intake of $\mathrm{Si}$ in men than in women [13, 14]. In both studies, beer consumption was the main contributor to the high $\mathrm{Si}$ intake in men $[13,14]$. Although beer may account for a substantial proportion of daily Si intake and has a high absorption rate, beer consumption varies greatly between individuals and none of the pregnant women in the present study consumed beer on a daily basis. The difference in urinary excretion levels of $\mathrm{Si}$ within the groups in the present study probably reflects differences in $\mathrm{Si}$

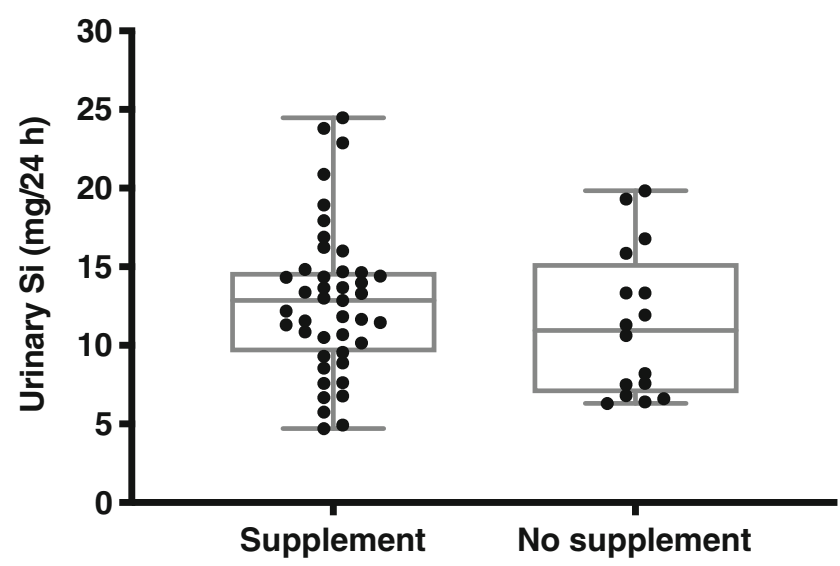

Fig. 2 Distribution of individual excretion levels of $\mathrm{Si}$ in urine samples from pregnant women taking dietary supplements $(n=43)$ and pregnant women not taking dietary supplements $(n=16)$. Each dot represents an individual subject, the whiskers shows the full data range (min to max), and the box shows the inter-quartile range 
intake but this is unlikely to be the cause for the higher Si excretion values observed for the whole group of pregnant women. Taken together, it is unlikely that these women, in an early stage of pregnancy, would have increased or changed their food intake pattern to such an extent that it would be reflected in the significantly higher levels of $\mathrm{Si}$ excretion. Another possible reason for the increased urinary levels of $\mathrm{Si}$ in the pregnant women is nutritional supplementation. However, none of the consumed supplements had $\mathrm{Si}$ as the active ingredient, and the majority of these products contained negligible amounts of $\mathrm{Si}$ (as an additive) in a non-bioavailable form. In addition, statistical analysis reveals no significant difference in urinary excretion levels of $\mathrm{Si}$ between pregnant women taking supplements and those not taking supplements.

Pregnancy poses many physiological changes in terms of meeting the demands of the growing foetus. During pregnancy, the placenta actively transports bone-essential elements, primarily calcium $(\mathrm{Ca})$ and phosphorus, to the foetus in order to ensure sufficient mineral concentrations for the developing skeleton [30]. The increased need for $\mathrm{Ca}$ is met not only by enhanced gastrointestinal absorption [31] but also possibly by a modified bone status in the mother [30]. It has been suggested that maternal bone mass decreases in the early stages of pregnancy due to an initial phase of bone remodelling [30]. Furthermore, higher urinary excretion of $\mathrm{Ca}$ is seen in early pregnancy and an increased glomerular filtration rate is also a possible influencing factor behind the elevated excretion levels [31]. As Si has been proposed to be important for the normal development of bone $[6$, $7,32]$, it is possible that $\mathrm{Si}$ is regulated by enhanced absorption and bone metabolism similarly to Ca during pregnancy.

Fasting serum levels of Si could provide further understanding of a potentially altered Si metabolism in pregnant women, but unfortunately the studies in which serum Si levels have been assessed during pregnancy show contradictory results $[33,34]$. In one study, significantly lower serum Si levels were reported in pregnant women, as compared with nonpregnant women and the suggested reason for this is that $\mathrm{Si}$ is re-distributed from the mother to the growing child for connective tissue development [33]. The lower serum levels of $\mathrm{Si}$ in the mothers could also be explained by an expanded plasma volume and consequent haemodilution. Interestingly, the same study also showed significantly increased serum levels of $\mathrm{Si}$ in infants ( $<1$ year of age) compared with adolescents and adults [33]. A more recent study found no significant differences in the serum Si levels between pregnant and non-pregnant women, but reported higher Si levels in the cord blood of new-borns compared with their mothers at birth [34].

\section{Conclusion}

This is the first study to investigate urinary $\mathrm{Si}$ excretion in pregnant women and we report that pregnant women have significantly higher 24-h urinary Si excretion levels, compared with the non-pregnant women and men investigated in the current study and compared with previous studies of healthy men and women. We report that this does not appear to be due to altered renal function (urine volume or creatinine excretion). However, as dietary intake was not assessed, we cannot dismiss marked differences in Si intake, although this seems unlikely. A more likely reason for the higher urinary $\mathrm{Si}$ excretion in pregnant women is temporary physiological changes such as increased gastrointestinal absorption of $\mathrm{Si}$, altered bone metabolism, and renal excretion of $\mathrm{Si}$, and this deserves further investigation in future studies.

Funding This study was supported by grants from TUA Research Funding, The Sahlgrenska Academy at the University of Gothenburg, Region Västra Götaland, Sweden and the Medical Research Council of UK (grant reference number MR/R005699/1).

\section{Compliance with Ethical Standards}

Ethical Standards The study was conducted according to the Ethical Principles for Medical Research Involving Human Subjects, formulated in Helsinki, Finland, in June 1964 and amended by the 64th World Medical Association General Assembly, in Fortaleza, Brazil, in October 2013. The protocol for the GOOD study of young men was approved by the Regional Ethics Review board in Gothenburg (nos. 600-02, 075-03), the study of women (no. 564-03), and the study of pregnant women (nos. 012-06, 051-07). The participants were given written information about the study and they gave signed informed consent.

Conflict of Interest The authors declare that they have no conflict of interest.

Open Access This article is distributed under the terms of the Creative Commons Attribution 4.0 International License (http:// creativecommons.org/licenses/by/4.0/), which permits unrestricted use, distribution, and reproduction in any medium, provided you give appropriate credit to the original author(s) and the source, provide a link to the Creative Commons license, and indicate if changes were made.

\section{References}

1. Rodan GA (1992) Introduction to bone biology. Bone 13(Suppl 1): S3-S6

2. Gennari C (2001) Calcium and vitamin D nutrition and bone disease of the elderly. Public Health Nutr 4(2B):547-559

3. Jugdaohsingh R, Pedro LD, Watson A, Powell JJ (2015) Silicon and boron differ in their localization and loading in bone. Bone Rep 1:9-15. https://doi.org/10.1016/j.bonr.2014.10.002

4. Mladenovic Z, Sahlin-Platt A, Andersson B, Johansson A, Bjorn E, Ransjo M (2013) In vitro study of the biological interface of BioOss: implications of the experimental setup. Clin Oral Implants Res 24(3):329-335. https://doi.org/10.1111/j.1600-0501.2011.02334.x

5. Carlisle EM (1970) Silicon: a possible factor in bone calcification. Science 167(3916):279-280

6. Carlisle EM (1972) Silicon: an essential element for the chick. Science 178(4061):619-621 
7. Schwarz K, Milne DB (1972) Growth-promoting effects of silicon in rats. Nature 239(5371):333-334

8. Reffitt DM, Ogston N, Jugdaohsingh R, Cheung HF, Evans BA, Thompson RP, Powell JJ, Hampson GN (2003) Orthosilicic acid stimulates collagen type 1 synthesis and osteoblastic differentiation in human osteoblast-like cells in vitro. Bone 32(2):127-135

9. Mladenovic Z, Johansson A, Willman B, Shahabi K, Bjorn E, Ransjo M (2014) Soluble silica inhibits osteoclast formation and bone resorption in vitro. Acta Biomater 10(1):406-418. https://doi. org/10.1016/j.actbio.2013.08.039

10. Jugdaohsingh R, Tucker KL, Qiao N, Cupples LA, Kiel DP, Powell JJ (2004) Dietary silicon intake is positively associated with bone mineral density in men and premenopausal women of the Framingham Offspring cohort. J Bone Miner Res 19(2):297-307. https://doi.org/10.1359/JBMR.0301225

11. Bellia JP, Birchall JD, Roberts NB (1994) Beer: a dietary source of silicon. Lancet 343(8891):235

12. Reffitt DM, Jugdaohsingh R, Thompson RP, Powell JJ (1999) Silicic acid: its gastrointestinal uptake and urinary excretion in man and effects on aluminium excretion. J Inorg Biochem 76(2):141-147

13. Pennington JAT (1991) Silicon in foods and diets. Food Addit Contam 8(1):97-118. https://doi.org/10.1080/02652039109373959

14. Jugdaohsingh R, Anderson SH, Tucker KL, Elliott H, Kiel DP, Thompson RP, Powell JJ (2002) Dietary silicon intake and absorption. Am J Clin Nutr 75(5):887-893

15. Kim YY, Kim MH, Choi MK (2019) Relationship between dietary intake and urinary excretion of silicon in free-living Korean adult men and women. Biol Trace Elem Res. https://doi.org/10.1007/ s12011-018-1619-0

16. Powell JJ, McNaughton SA, Jugdaohsingh R, Anderson SH, Dear J, Khot F, Mowatt L, Gleason KL, Sykes M, Thompson RP, BoltonSmith C, Hodson MJ (2005) A provisional database for the silicon content of foods in the United Kingdom. Br J Nutr 94(5):804-812

17. Sripanyakorn S, Jugdaohsingh R, Elliott H, Walker C, Mehta P, Shoukru S, Thompson RP, Powell JJ (2004) The silicon content of beer and its bioavailability in healthy volunteers. Br J Nutr 91(3):403-409. https://doi.org/10.1079/BJN20031082

18. Robberecht H, Van Dyck K, Bosscher D, Van Cauwenbergh R (2008) Silicon in foods: content and bioavailability. Int J Food Prop 11(3):638-645. https://doi.org/10.1080/10942910701584252

19. Sripanyakorn S, Jugdaohsingh R, Dissayabutr W, Anderson SH, Thompson RP, Powell JJ (2009) The comparative absorption of silicon from different foods and food supplements. Br J Nutr 102(6):825-834. https://doi.org/10.1017/S0007114509311757

20. Dobbie JW, Smith MB (1986) Urinary and serum silicon in normal and uraemic individuals. CIBA Found Symp 121:194-213

21. Pruksa S, Siripinyanond A, Powell JJ, Jugdaohsingh R (2014) Silicon balance in human volunteers; a pilot study to establish the variance in silicon excretion versus intake. Nutr Metab (Lond) 11(1):4. https://doi.org/10.1186/1743-7075-11-4

22. Lorentzon M, Mellstrom D, Ohlsson C (2005) Age of attainment of peak bone mass is site specific in Swedish men-the GOOD study. $\mathrm{J}$
Bone Miner Res 20(7):1223-1227. https://doi.org/10.1359/JBMR. 050306

23. Hulthen L, Aurell M, Klingberg S, Hallenberg E, Lorentzon M, Ohlsson C (2010) Salt intake in young Swedish men. Public Health Nutr 13(5):601-605. https://doi.org/10.1017/S1368980009991431

24. Lissner L, Sjoberg A, Schutze M, Lapidus L, Hulthen L, Bjorkelund C (2008) Diet, obesity and obesogenic trends in two generations of Swedish women. Eur J Nutr 47(8):424-431. https:// doi.org/10.1007/s00394-008-0744-5

25. Johner SA, Boeing H, Thamm M, Remer T (2015) Urinary 24-h creatinine excretion in adults and its use as a simple tool for the estimation of daily urinary analyte excretion from analyte/creatinine ratios in populations. Eur J Clin Nutr 69(12):1336-1343. https:// doi.org/10.1038/ejen.2015.121

26. Burden TJ, Powell JJ, Thompson RPH, Taylor PD (1995) Optimal accuracy, precision and sensitivity of inductively coupled plasma optical emission spectrometry: bioanalysis of aluminium. J Anal At Spectrom 10(3):259-266. https://doi.org/10.1039/JA9951000259

27. Jugdaohsingh R, Sripanyakorn S, Powell JJ (2013) Silicon absorption and excretion is independent of age and sex in adults. Br J Nutr 110(6):1024-1030. https://doi.org/10.1017/S0007114513000184

28. Dobbie JW, Smith MJ (1982) The silicon content of body fluids. Scott Med J 27(1):17-19. https://doi.org/10.1177/003693308202700105

29. Berlyne GM, Adler AJ, Ferran N, Bennett S, Holt J (1986) Silicon metabolism. I. Some aspects of renal silicon handling in normal man. Nephron 43(1):5-9

30. Salles JP (2016) Bone metabolism during pregnancy. Ann Endocrinol (Paris) 77(2):163-168. https://doi.org/10.1016/j.ando. 2016.04.004

31. Prentice A (2003) Micronutrients and the bone mineral content of the mother, fetus and newborn. J Nutr 133(5 Suppl 2):1693S1699S

32. Seaborn CD, Nielsen FH (2002) Silicon deprivation decreases collagen formation in wounds and bone, and ornithine transaminase enzyme activity in liver. Biol Trace Elem Res 89(3):251-261

33. Van Dyck K, Robberecht H, Van Cauwenbergh R, Van Vlaslaer V, Deelstra H (2000) Indication of silicon essentiality in humans: serum concentrations in Belgian children and adults, including pregnant women. Biol Trace Elem Res 77(1):25-32. https://doi.org/10. 1385/bter:77:1:25

34. Jugdaohsingh R, Anderson SHC, Lakasing L, Sripanyakorn S, Ratcliffe S, Powell JJ (2013) Serum silicon concentrations in pregnant women and newborn babies. Br J Nutr 110(11):2004-2010. https://doi.org/10.1017/S0007114513001578

Publisher's Note Springer Nature remains neutral with regard to jurisdictional claims in published maps and institutional affiliations. 